\title{
A Few Remarks on the Theory of Finance ${ }^{1}$
}

The well-known Russian historian Yevgeny Tarle wrote in his History of Europe 1871-1919² that "in the first years after the war of 1914-1918 some financiers expressed the view that: "none of the rules of the socalled theory of finance had any scientific, i.e. compelling ${ }^{3}$ significance, and could not have, because so-called "financial law" in its entirety was an attempt to construct an allegedly scientific theory from the longstanding customs of 19th-century financial life”.

The mention of the "financial customs" of the 19th century seems to indicate that this historian had public finance in mind; and it is public finance that shall be discussed below. It is not known, in turn, if "some financiers" were practitioners or theoreticians in the area of finance. ${ }^{4}$ Perhaps it would be going too far to believe that there is a big gap between practitioners and theoreticians in the way they understand finance; the former too often believe the latter to be doctrinaires, while the latter consider the former to be some kind of passive tools. Nevertheless, a difference between the views of theoreticians and practitioners is sometimes

1 Translated from J. Zdzitowiecki, Parę uwag wokół teorii finansów, "Ruch Prawniczy Ekonomiczny i Socjologiczny”, 1972, 2, pp. 95-109 by Tomasz Żebrowski and proofread by Stephen Dersley and Ryszard Reisner. The translation and proofreading were financed by the Ministry of Science and Higher Education under 848/2/P-DUN/2018.

2 Y. Tarle, Dzieje Europy 1871-1919, Warszawa 1961.

3 Let's ignore the question if "scientific" indeed means the same as "compelling".

4 The quoted author did not give any name in this context. I shall follow his example in this article. 
noticeable, with the impact of practitioners being easily noticeable in various publications as well. Views resembling those of Yevgeny Tarle quoted at the beginning have been expressed for a long time by authors more or less rightly considered to be - and considering themselves theoreticians of financial matters.

When considering the early years of financial studies, a search for purely theoretical deliberations would prove to be in vain. In those times, journals were published for practical purposes and this continues to be the case, with success, ever since. There are plenty of authors who believe financial studies to be a kind of practical skill, an art close to a craft, denying its practitioners any ability to think in more general, not to say, abstract terms. The task of financial studies understood in this way is drawing up recipes or rules of conduct for the government and its financial agencies. A note of impatience and disdain for what can neither be immediately implemented nor revealed in practical life can be detected in this view. As if it were not familiar knowledge that research results can only seldom be immediately applied in practice. It was such direct ends that the authors of financial articles had in mind in the times of cameralism or of so-called political arithmetic. A certain dislike for theoretical inquiries may stem from too hastily drawing practical conclusions (sometimes ultimately proving to be highly impractical) from only sketchy scientific views (or theories). Not infrequently, they are rather more like preliminary outlines than completed wholes. Alternatively, hasty conclusions are drawn from insufficiently studied theoretical views, even though such views have fully elaborated.

All these diverse misunderstandings cause today's financial studies to be supposedly far from perfect, in the opinion of many contemporary authors from various countries. The studies allegedly lack any theoretical underpinnings and are a more or less chaotic collection of casual observations. This comes as no surprise, since the very concept of "finance", although commonly used both in academic discourse and colloquial speech, has allegedly not been defined accurately enough yet. 
Theoretical questions arising from the study of the legal-financial situation, are supposedly tangled in a "maze of problems", which, in particular, financial-law studies have not been able to order and elucidate yet. When the state of financial science is painted with such colours-to which others will be added below-it will not be surprising to hear that this discipline lags behind many other fields of learning and attracts little interest.

Although in traditional financial studies, too, a great deal of space has been given to the technical aspect of financial phenomena, the modern-day professional literature devotes so much attention to these organisational and technical questions that the impression is sometimes created of the entire field of financial studies being largely concerned with the forms and methods of accumulating and using monetary resources. Alternatively, activity in the field of finance is held to be propelled by a single trend of social life. Meanwhile, life as we know it is rather complex and lends this complexity to finance.

Major advances in the technical and natural sciences, which it was possible to put into effect without much delay or hindrance, have pushed the humanities into the background. The latter's conclusions do not lend themselves to easy implementation or palpable verification. The successes of technical and natural sciences have thus influenced the social sciences, including financial studies. In this field, too, matters have begun to be counted first, before they are weighed, to the neglect of the old truth which had been expounded in writing in the latter half of the 18th century, that it is precisely in finance that two times two rarely makes four, but usually less or more. Thus, financial studies have also reflected this new positivism - we can use this term here-and bent their interest towards the search for a technical means of managing the monetary matters of the State. Incidentally, the considerable impact of finance practitioners is also evident in this area; those who confidently busy themselves today not only with current affairs but also long-term forecasts. 
One more trait: perhaps not concerning studies as much as teaching (as a matter of fact, they are sometimes hard to separate: all that is known is that without the former, the latter should not be done). Teaching — at the tertiary level—-too often tends to convey to students longer or shorter summaries of the legal norms in force (not only in the area of financial law, but also in the area of "finance"). This is done by explaining (which is actually necessary) commonly used concepts (not to say: names) and sometimes calling this part of the course the "theory of finance”, or some such. Alternatively, being convinced that this is satisfactory, a historical approach to the subject is limited to the enumeration of successive occurrences. A reservation must be made in this context, namely that both the knowledge of the law and the sequence of occurring phenomena are necessary but insufficient. This way of teaching, meeting the above description more closely on one occasion and less so on another, seems, however, to be rather anachronistic today and appears to have been inherited perhaps from the 19th-century custom, or maybe an even older one. The capitalist State at that time (particularly earlier ones) made do with a relatively modest number of regulations concerning its finance. The reasons for this are well known and need not be mentioned here. To become familiar with all these regulations and learn them was perfectly possible, while today there are so many financial norms that the old teaching method has become glaringly absurd and would be best replaced with another. How to do this is another story. Suffice to say that the present teaching method seems to be influenced by the custom of primarily focusing on techniques and descriptions.

In many countries a lot of books are published, often very useful ones, but in most cases they are focused on teaching (textbooks) rather than research, or they are produced for propaganda purposes. Of course, even such publications may not be indifferent to the study of finance, but their main purpose obviously is not to make a contribution to knowledge. In all ages, financial matters were dealt with by historians, philosophers, jurists, economists, politicians and even theologians. Perhaps it 
is for this reason that such studies, intended to be purely financial, often suffer from a confusion of subjects and the muddling of a strict theoretical analysis and synthesis with other approaches, either for pedagogical purposes (textbooks) or descriptive ones, or for making a dry presentation of the law in force.

Financial studies are based on and tap into, so to speak, many other branches of knowledge, which makes it quite difficult to stake out their proper purview. A well-known truth must be remembered in this context, namely that he who tries to embrace too much, does not hold firmly. If one wanted to consider financial matters in the broadest possible manner, one would run the risk of the treatise spilling in all possible and impossible directions. The certain outcome here would be a situation wherein readers would learn a lot of admittedly interesting details, but they would not learn the most important thing: what finance actually is and what financial studies treat of. Perhaps it is because our discipline sometimes tries to shoulder too much, while not always being able to bear the burden, that we can sometimes hear the opinion that actually there are not any financial studies, because those engaged in financial studies consider the discipline to deal with issues that have long been addressed by other branches of knowledge. Some kind of tolerance is still sometimes enjoyed by financial law, however.

After all, it is not necessary to conclude that financial studies do not exist, and that one can speak only of conditions conducive to the development of a financial theory. For this discipline and this theory do indeed exist, and have been around for some time. Admittedly, some publications circle around the keys issues, so to speak, being unable to get down to the heart of the matter, but cannot the same be said of all branches of knowledge?

Similarly to other branches of learning, financial studies or theory faces similar preliminary problems that must be prioritized. Namely, where to draw its boundaries, i.e. what its purview is, what its object should be and, finally, whose activity it is to take care of or what its 
subject is. A certain difficulty lies in the fact that various disciplines can study the activity and character of the same subject; in other words, the criterion according to which branches of learning are distinguished is the point of view taken to observe a given subject -and not so much a criterion derived from the subject itself.

In every discipline, defining it means a certain restriction of its subject matter. In particular, in research it is absolutely necessary to draw some boundaries within which a certain body of inquiries is to stay. Of course, all restrictions entail some discretion, if only in order to facilitate research. Probably in no branch of learning can an absolutely precise definition be found, including the definition of its subject. Moreover, definitions may change due to a change in the point of view or the passing of time. If, therefore, this or that definition of financial studies appears to somebody to be too narrow, let them expand it, provided that the expansion is logically justified and the homogeneity of the studied subject is kept.

However, whatever boundaries are drawn for the subject of their studies by this or that researcher in the field of finance, common agreement or unanimity can hardly be expected in this respect. Any administrative order imposing some golden agreement, although this could have been attempted in the past, would bring one result, namely making research barren. Making financial studies as broad as possible, ignoring even the rather imprecise meaning of the adjective, would be viewed by some as doing the greatest service to this branch of knowledge, while others would consider this an inflation of the subject and a hindrance to its accurate treatment. Both would be right if they succeeded in their tasks, attaining lucidity and maintaining logic in their publications.

In financial studies this is not so easy, because the prevailing opinion is that this discipline is concerned with public finance in general and sometimes, albeit in a narrower scope but in greater detail, with the finance of the State. The State, in turn, is an organism embracing the many areas of life of a country, but in the first place it is a political organism. ${ }^{5}$

5 This is not the place to discuss what the term "political” means. 
It conveys this important characteristic to the study of its finance, hence making the study political as well.

The heart of the political character of the State is its supreme authority and the fact that it has the attribute of power. The finances of the State, as the supreme authority, naturally fit into the concept of public finance, with the latter encompassing all the branches of finance whose subjects have-perhaps it might be said_-admittedly a social character but they lack the attribute of supreme political authority. In turn, the question who, or what subject, can be attributed supreme political authority, although it can be subjected to scholarly deliberations, is settled by the country's political system, specifically, its constitution. Hence, in various countries the question may take a different form, which, however, should not hinder attempts to draw a general picture.

The right of the State (i.e. its bodies) to perform "acts of authority", its superiority in respect of various other subjects, seems to be a sufficiently clear criterion in a more or less general discussion of the question. Such a discussion is by no means easy: Mr Zagłoba noticed a long time ago that "not everybody can think in general terms" ${ }^{6}$ Of course, the term "State finance" does not cover all the fields where financial activities are conducted. They transpire in various other fields as part of the activities of various organisations, associations, etc. The financial activity in other fields, i.e. apart from the State as an organisation of supreme authority, is sometimes studied as well. This, however, is already such a broad scope that it may be considered part of financial studies only if they are understood so broadly that they would be better called general or universal financial studies. It is doubtful, however, if such a broad and loose a treatment would ensure satisfactory coherence and clarity of argument. It might be better to draw clear lines indicating where to stop the study of each branch of this universality; thus, for instance, we would have state finance, finance of the national economy (enterprises), etc. Such distinc-

6 Had he known the author of this disquisition, he would have certainly confirmed in this conviction. 
tions would not be, even in the slightest, a juxtaposition of one area of financial studies with another: on the contrary, they would supplement one another. Only when the boundaries between the domains of different sciences and different areas in the same universal financial studies are blurred, is one indeed faced with a "maze of problems" that are hard to get out of. The boundaries between the financial studies of the State and, for instance, the financial studies of the national economy (enterprises) are quite clear - they can be defined with satisfactory accuracy, provided that a clear criterion of division is chosen. The ability to define clearly the field of study is a necessary condition of clarity and-if this is the right word - the effectiveness of inquiries.

Naturally, any financial activity is influenced by various social factors and trends affecting a country at a given time. To be keenly aware of this and, more importantly, of the diverse consequences - not only financial ones - of some form of conduct for a seemingly isolated field of finance is a necessary condition for the successful use of a financial instrument. Again, it is a matter of noticing the limits of effectiveness of an intended endeavour. All this can be easily learned and sometimes even seen. Such an expansion of the purview of financial studies beyond strict boundaries may result in encroaching on the otherwise interesting fields of study and the experience of sociology or economic policy, but will also introduce into the purview such elements that are imperceptible to the financial studies of the State, which may obscure their picture. It would be better for the studies to stay within the boundaries drawn for financial activity by the constitution and other written and common law. Even if the consequences of law are not always predictable, at least motives behind legal norms and the mechanisms of their enactment would be known in advance. This seems to be an elementary requirement of the rule of law.

The question of the purview of financial studies is not exhausted upon realising what their subject is, upon finding whose finances are to be studied. No less important, the determination of what phenomena 
ought to be considered financial shows what the proper object of financial studies is. On this matter, too, opinions vary: they are either expressed explicitly or can be gleaned indirectly from the professional literature. In any event, only after determining the object and subject of research is it possible to draw a general picture of the field, to build financial studies in the fuller sense of this concept and, ultimately, to develop a theory of finance. However, even an absolutely accurate determination of the subject and object of financial studies may prove insufficient for building complete financial studies or an all-round theory of finance when the subject and object are, for a change, too narrow in scope. In such a case, a certain fragment of the material can be presented, which could be otherwise beneficial and may later facilitate a comprehensive approach to the subject matter, but obviously falls short of it for the time being. In turn, a mechanical compilation of many such particular publications will not produce financial studies or a theory of finance.

A frequently encountered definition of the object of finance, and thus of its study, maintains that it is consists of financial activity (or that financial studies are concerned with such). Obviously, such a dry explanation did not explain anything (idem per idem) and an additional description was necessary as to what the "financial” attribute was (in this case, primarily of the State). Indeed, many authors writing on these matters came up with such explanations, quite rightly so, but almost all of them explained it in their own way. Hence, the selection of explanations is wide, e.g. a theory of exchange, theory of consumption, production, reproduction, etc. Without going into details, we can cite the view that the object of finance and its studies is the activity of the State aimed at accumulating funds to pursue its goals. This suffices for the time being, but this view clearly focuses attention on the outer shell of the financial activity, to the neglect of its economic aspects or other content. This over-generalised definition is usually supplemented by authors writing on financial matters with various additional explanations, which are sometimes quite significant, but which on other occa- 
sions threaten to sidetrack the issue or, worse, lead it up a blind alley. To give an example: when too much stress is laid on the "movement of monetary resources" accompanying production or reproduction, it is easy to lapse into the ways of simple bookkeeping or accounting, which are useful technical skills. Although financial relations do indeed have a quantitative expression, seeking their sense only in the form in which they occur and observing only the vicissitudes and methods of monetary transactions would be to remove the content from finance and to break the ties between finance and a country's other spheres of life, such as the economy, and between finance and moral aspects, etc. The significance of latter aspects for social life should not be ignored.

The accumulation of funds and their successive distribution, the collection of revenue and incurring expenses, i.e. the manipulation of funds and recording all these acts in accounts and reports, is rather organisational and technical work. These acts are performed, so to speak, before or after the production process and outside the process of distributing and producing goods, while in fact they are-or should be-a component of both these processes. Financial acts do not merely consist in mechanically moving sums of money from one account to another, but are an element helping in the generation and distribution of the national income. The task of financial studies is not merely to record the movement of goods appraised in money; it is also important to consider how and to what degree movements of sums of money contribute to the rise of the national income and its better distribution. Finance is thus one element of the national economy that should be harmonised with its other elements, both tangible and intangible.

However, even if an author writing on financial matters succeeded in unexpectedly clearly and accurately identifying the subject of financial activity and financial studies, if they were able to define the object of considerations equally well, they would face another considerable difficulty, namely how to present financial studies to the general public. It would not be a question of choosing one of those methods of de- 
scribing subjects that can be learned from elementary logic textbooks. In principle, every branch of learning, including financial studies, should be characterised by a certain unity and coherence of issues it deals with.

Meanwhile, although its object appears to be quite simple from the point of view of everyday financial practice, from the scholarly angle it looks quite different, if only because matters are discussed critically in this case. The occurrences and processes that financial studies usually deal with are made up of not only financial elements — on the contrary, they sometimes result from manifold causes and their consequences are no less complex. Thus, they are not only strictly fiscal but also, and sometimes predominantly, non-fiscal: either economic, social or political, or even of a moral character. It is for this reason that the same question, which apparently concerns finance only, may be and sometime is studied by various scholarly disciplines, while financial studies only illuminate one of its aspects (if at all). Financial institutions or acts, i.e. concerning State finance, are endeavours of the State and thus are not only economic, but also (sometimes predominantly) political. An additional and serious difficulty lies in the fact that it is not always possible to "translate" financial occurrences into economic ones or others, and vice versa. This could be one of the sources of the well-known truth mentioned earlier - that in finance two times two almost never makes four... Hence, the quantitative examination of just the turnover of monetary resources will almost never fully explain financial matters. As a matter of fact, all this should be quite understandable: not all relations between people or other groups are purely economic or ones that can always be calculated in money. The multiplication table (sometimes, a division table and most often a subtraction table ...) is not a key to omniscience.

Not only is the current financial reality multicoloured and changeable, but the characteristics of finance change with time as well. State finance is not a recent invention; sometimes the roots of some presentday financial institutions hark back to a distant past. 
The form financial institutions take is peculiar to the age in which they function, while in the same age, various countries and their political systems give them their own specific appearance. General financial studies may, so to speak, appeal to financial archives and present matters as they developed from ancient to more recent times. Alternatively, an attempt may be made to present matters in a general way: how they looked in a single selected age. Changes in financial reality are usually paralleled by changes in their theoretical illumination in financial studies and in the theory of finance. Research of two kinds has been undertaken. One concentrates on all the financial matters of the State. This is the domain of general financial studies. The other enquires into individual fields of finance and is undertaken by detailed financial studies. The former attempts to build a theory of finance, while the latter provides material for the former to be successful.

Of these and other difficulties in the scholarly analysis of financial matters, various ways out were attempted, from too simplistic to overly complicated ones. Thus, one may encounter financial studies or a theory of finance that is a mere enumeration of the financial institutions in existence in a given country. No reference is made to the legislation that has provided for their formation and prescribes the mode of their operation. Textbook chapters devoted to them sometimes bear the titles "Financial Studies" or "Theory of Finance". In turn, a chapter with the same content but supplemented with references to relevant legislation is entitled "Financial Law". This approach to the subject matter differs from a scholarly one as much as a chronicle differs from history.

Such a "chronicle" is normally supplemented with a description of financial institutions and acts. A well-drafted description brings us closer to the knowledge of the subject-matter, and as such is a necessary and useful endeavour, but like a "pure" presentation of financial reality which uses statistical tables or other accounting graphics, it is merely a set of information on the finance of a given country, and cannot be described as financial studies. Even if such a description-even a cor- 
rect one-were augmented by an assessment in the indicative mood of a "judgement", this would not lend any characteristics of science or theory to it.

It may certainly happen that a financial dissertation will be thoroughly scholarly and theoretical throughout, but ultimately it must be admitted that descriptive publications, too, sometimes have passages of such a character. The same is true for publications whose intended goal is a generalisation. This is a difficult task, as even a generalised description remains a description, with the danger of the generalisation becoming an overly superficial, conventional and hasty review.

The State is a political organism and passes this characteristic to the study of its finance, which means that the study is one of political studies. The characteristic is to be broadly understood and extended to social matters as well. However, it must be remembered that it is not the only characteristic that marks out the area of financial activity and that the size of the area is given from above, so to speak, by the political system of the State and goals it attempts to achieve.

It might be preaching to the converted if the reader is reminded that scholarly and political activities differ in character. This is not in the least about which of these activities deserve more attention or praise: the task of learning is to discover the truth, while politics attempts to achieve objectives that are considered necessary at a given time. The difference resembles that between learning and art. Both spheres, although preferably interlinked, obviously are not identical. Learning or a theoretical approach is about learning the truth, discovering the forces at play in a given field and the rules governing it, explaining phenomena and identifying their causes, and anticipating probable consequences. However, it is not the task of learning to give practical guidelines. In learning, knowledge is allimportant, while in practice it is the will that prevails. Even the strongest will, if it ignores knowledge, is doomed to groping in the dark, while even the most profound knowledge without a sufficiently strong will to implement its findings will gather dust on library shelves. 
To this day, too many people see financial studies only as an art, unable to use the scientific method of building general theoretical concepts, an art whose only task is to develop practical recipes for the everyday operations of financial offices. Such recipes have little or nothing to do with scholarship, although, on the other hand, one should not allow oneself to be influenced by the form in this case, which might resemble a "recipe", but actually have some scholarly content. To illustrate the point, Vilfredo F. Pareto once used the following example. Two propositions: the first being that to calculate the area of a rectangle it is necessary to multiply its base by its height, and the second being that it is necessary to love one's neighbour as yourself, differ fundamentally. In the former, it is possible to strike out the words "it is necessary" and simply say that the area of a rectangle equals its base multiplied by its height, whereas in the latter, the words "it is necessary" cannot be struck out and thus the second proposition is not scholarly.

In the field of finance, there are no perpetually perfect practical guidelines or recipes. Situations in which they may be helpful change, and each new situation may demand different practical solutions, without undermining the fundamental achievements of scholarly research. Besides, the concept of financial practice encompasses not only some norms and regulations, etc. but also action. Furthermore, in finance there are no universal practical solutions, ones that are unique and identical for all countries wherever on earth they are located. The results of more fundamental scholarly research just enjoy a slightly longer life and a more general significance.

Having said that, it is better to be wary of doctrinaire one-sidedness and mindful of the fact that in the field of finance, as a matter of fact similarly to many others, the achievements of theory and experiences of practice should be continually exchanged and it would be undesirable if any of these trends or both were hampered by a dull doctrine or a carefree daily routine.

In the development path of financial studies, presumably as in the paths of other branches of knowledge, many different obstacles accrue. 
Certainly, a more comprehensive list of such obstacles could be drawn up than those mentioned above.

Of course, in order to be able to undertake the task of describing financial studies or advancing a theory of finance, it is helpful to be aware of not only what "finance" is and whose finance is to be studied, but also what approach to the subject should be called its studies or theory. However, it is only with difficulty, if at all, that a definition of any branch of learning could be found that would be unreservedly accurate. Apart from the fact that any definition assumes certain knowledge of the subject on the part of the person for whom it is expounded (i.e. in most cases, the reader of a given publication), a difficulty lies here also in the fact that the object of knowledge and investigated situations are rather complex, and the choice of this or that characteristic as crucial for the definition is not always objective. To compound matters even more, the defined object and situations change with time or under other circumstances, and sooner or later any definition simply ages and calls for a revamping.

A study or theory is in principle therefore a certain generalisation of experience, but obviously in the very process of generalising, the guiding mind of a researcher is necessary. An objective phenomenon in itself may not say or show anything to one person, but a lot to another. A description of phenomena or occurrences is not yet a study or a theory. Only when certain general rules or regularities are inferred from their course, i.e. when the phenomena or occurrences are subjected to mental processing, do they become a study or theory. The regularities discovered in this manner and the direction of their occurrence are related to many other processes, taking place in various fields, which are also an object of scholarly studies. However, the existence of a phenomenon itself may be borne out, whereas general regularities inferred from it may not be confirmed until some palpable results anticipated by it are obtained. The scholarly explanation alone of what the reality is, or what overall guiding regularities it is subject to, i.e. the knowledge 
of the subject matter, is in itself already a process and a state attracting understandable scholarly interest. However, it is also good to know that the acquisition of knowledge may entail more or less multifarious consequences in life. An unbridgeable gap between theory and "life" seems not to be possible, despite the fact that a theoretician is not necessarily and not always the person who puts the achievement of their branch of learning into practice at the same time. That division of labour between knowledge, theory and practice is only natural, and apparently it is necessary. In reality, the knowledge of a theoretician is combined with the actions of a practitioner into a peculiar whole. Thus, financial studies and the theory of finance, leading to practical actions, do not cease to be a scholarly endeavour, while practice, owing to its use (hopefully!) of the results of studies in life does not become a scholarly endeavour.

The ties between financial studies and practice in this field do not, or at least should not, restrict the studies to only to the most minute description of the currently existing reality, the explanation of today's phenomena and the indication of their and only their immediate consequences. In fact, it is necessary for financial studies, making use of all options, to advance certain general principles that might initially seem quite detached from life today. These would be general guidelines for a relatively more distant future that might only find their way to practice tomorrow. These would be the general laws, indications or illuminations that are part and parcel of the theory of finance (sometimes called the pure theory of finance) and that must be formulated in reliance not only on very narrowly understood purely financial phenomena, but also on substantial evidence from other spheres of life and branches of learning. These general scholarly financial laws not only border on existing social regularities, but sometimes have the character of postulates for future implementation: they speak of not so much how things are as how they should be.

Admittedly, here and there, in various publications, a scornful attitude is taken to the idea of advancing general financial laws. It is be- 
lieved to be futile tinkering with generalities. However, it does not appear that this view is right. Undeniably, coming to know the truth is far more difficult than speculation in detached theses. The legitimacy of financial studies may be judged not as much by respect for their general principles as by comparing them with the results of their application to real life situations. However, for the results to emerge, one has to wait. Meanwhile, although life is in no hurry, people usually are... . Hence, they usually lambast the uselessness of the abstract discipline. Although in real life, only concrete institutions or financial systems exist, and purely theoretic constructs only rarely leave the pages of learned books, the latter are not useless, because they may serve as a point of departure for some action, may be used to assess reality, or may be adopted as a goal to be achieved in life. Without such a sui generis signpost, reality may go astray. A pillar of fire moved before Moses as he led his people to the Promised Land; they never approached it close enough to hold it in their hands, but finally it led them along the right way to a land flowing with milk and honey. Both theoretical inquiries and practical activity must set such a point of departure and destination for themselves. In financial studies it is good to know not only how things stand, but also how they should stand and how they may stand, which is not by any means the least important.

The clue that leads to the doorstep of financial studies is the understanding of what finance really is; this matter was already briefly discussed above. Considerable difficulties would be encountered by anybody who would see "finance", like ancient cameralism did, as a mere manipulation of funds, techniques of collecting revenue and incurring expenses, and entering these revenues and expenses in books of account, etc. The knowledge of these techniques is necessary in financial offices, but financial studies should reach deeper and further beyond the monetary sheen of financial phenomena.

The task of financial studies is first of all to become familiar with and explain reality; as a matter of fact, the same goal should be pur- 
sued by all branches of learning - unlike another goal specific to financial studies, i.e. making research results change reality in this or that way if the changes are considered necessary. Some other branches of learning do not set the latter goal for themselves by: e.g. astronomy wishes to come to know the reality of the field it investigates but so far it has not intended to make modifications to the revolutions of heavenly spheres.... Whether the changes which are sometimes aimed at, owing to the achievements of financial studies, will finally prove useful is another story. Financial phenomena and actions have their material content, they refer to certain occurrences with which, on the one hand, they originate, and on the other, to which they introduce changes, whether intended or not. The most easily perceptible content of financial phenomena and activity involves economic matters and certainly it is for this reason that the economic theory of finance is the most frequent topic of financial dissertations. However, finance, even if it is believed to have only economic content, ipso facto, fits into the purview of social matters; since at the same time finance is a sphere of State activity, it must have a political trait as well (as a matter of fact it is proper to finance also owing to the fact that, as was already mentioned, finance fits into the social sphere).

Thus the establishment and management of financial institutions are not done casually and randomly but are regulated by legal norms. The set of such norms makes up financial law. All these directions of financial activity and issues may and should be judged not only by their particular advisability — and sometimes they are- but also from the moral perspective. Finance, its content and tasks are an object of illumination or elucidation according to the views of particular authors writing on these subjects. However, finance itself is a domain where many various forces interplay; likewise, financial studies and theory are a joint effort, taking advantage of the investigative results of many other branches of learning. It might have been this aspect that made some authors writing on finance believe that there was no such thing as financial studies, and that 
it all amounted to a purely chaotic jumble of information which sometimes came to be mistakenly described as financial studies. Of course, if somebody wished to approach, for instance, financial law or financial policy as a set of separate pieces of information on this law or policy, they would be right to conclude that there was no general study of financial law or financial policy (i.e. one covering a broader section of life). An even broader opinion could be ventured that there is no theory (study) of financial law and even less of financial policy, because there is a single study or theory of finance (what its content would be depends on the convictions of its author or supporter) — one general branch of learning from which every branch of financial studies stems. Such a situation would be hardly imaginable if a theory of finance, theory financial law, etc. existed in parallel but remained separate. The name of financial studies or financial theory is deserved only by a branch of learning that is capable of explaining and formulating general laws in all the branches of finance. Financial studies or the theory of finance harmonises all such branches into a single homogenous system and does not scatter them around. The fact that harmonisation may take place on some relatively high level of scholarly abstraction does not contravene the rule at all.

The fact that financial studies in one period or another lean towards this or that aspect of research, such as a high theory, or at another time become mired in details of accounting should worry no one. Each period judges each branch of learning by its own standards but the whole will come together by itself some time anyway... Moreover, if this or that argument sometimes puts on the airs of theory, it will meet the same fate as in the fable by La Fontaine: La chétive pécore s'enfla si bien qu'elle creva.

\section{Literature}

Tarle Y., Dzieje Europy 1871-1919, Warszawa 1961. 
